\title{
Submental approach to intubation for craniomaxillofacial surgery
}

\author{
Jason K. Panchamia, DO • Denzil Hill, MD • Basel Sharaf, MD, DDS • \\ Adam W. Amundson, MD
}

Received: 3 December 2020/Revised: 21 December 2020/Accepted: 21 December 2020/Published online: 13 January 2021

(C) Canadian Anesthesiologists' Society 2021

\begin{abstract}
A 37-yr-old male (who consented to this report) involved in a high-speed motor vehicle accident presented to the operating room with maxillofacial injuries including bilateral Le Fort I and II fractures, nasal fractures, and dental malocclusion. His airway was patent. In collaboration with the surgical team, we decided to perform a submental intubation because of the patient's significant facial trauma and necessity to establish dental occlusion. After induction of general anesthesia, the patient was orally intubated using an armored endotracheal tube (ETT) that was modified by cutting it just distal to the tube connector that was then replaced with a fitted universal $15-\mathrm{mm}$ connector. A $1-\mathrm{cm}$ incision in the submental area was made and after blunt dissection, the surgeon created a soft tissue tunnel from the submental skin incision through to the floor of the mouth exiting in the right mandibular
\end{abstract}

lingual area (Figure 1, panels A and B). After tunnel formation, the ETT pilot balloon was pulled through the dissected tissue tract using a hemostat. The ETT was then disconnected from the ventilator, its connector was removed, and then the ETT was drawn through the tissue tunnel with the hemostat and exteriorized (Figure 1, panel C). The ETT was then re-connected to the ventilator and sutured to the submental skin to reduce the risk of dislodgement (Figure 1, panel D). At the end of the operation, the suture was released and the ETT was retracted back into the oropharynx; the patient was uneventfully extubated. The submental and intraoral incisions were closed with resorbable sutures to minimize saliva pooling in the submental soft tissues.

Submental intubation is an alternative to a tracheostomy in situations when oral and/or nasal airways are

J. K. Panchamia, DO (ه) · D. Hill, MD ·

A. W. Amundson, MD

Department of Anesthesiology and Perioperative Medicine,

Mayo Clinic, Rochester, MN, USA

e-mail: Panchamia.Jason@mayo.edu

B. Sharaf, MD, DDS

Department of Plastic and Reconstructive Surgery, Mayo Clinic, Rochester, MN, USA 
Figure 1 A) Soft tissue dissection from the submental space to the floor of the mouth; B) submental tunnel established along lingual surface of the right mandible; C) pilot balloon and endotracheal tube (ETT) pulled through the newly formed tunnel using a hemostat; D) the ETT is reconnected to the ventilator and secured to the chin.
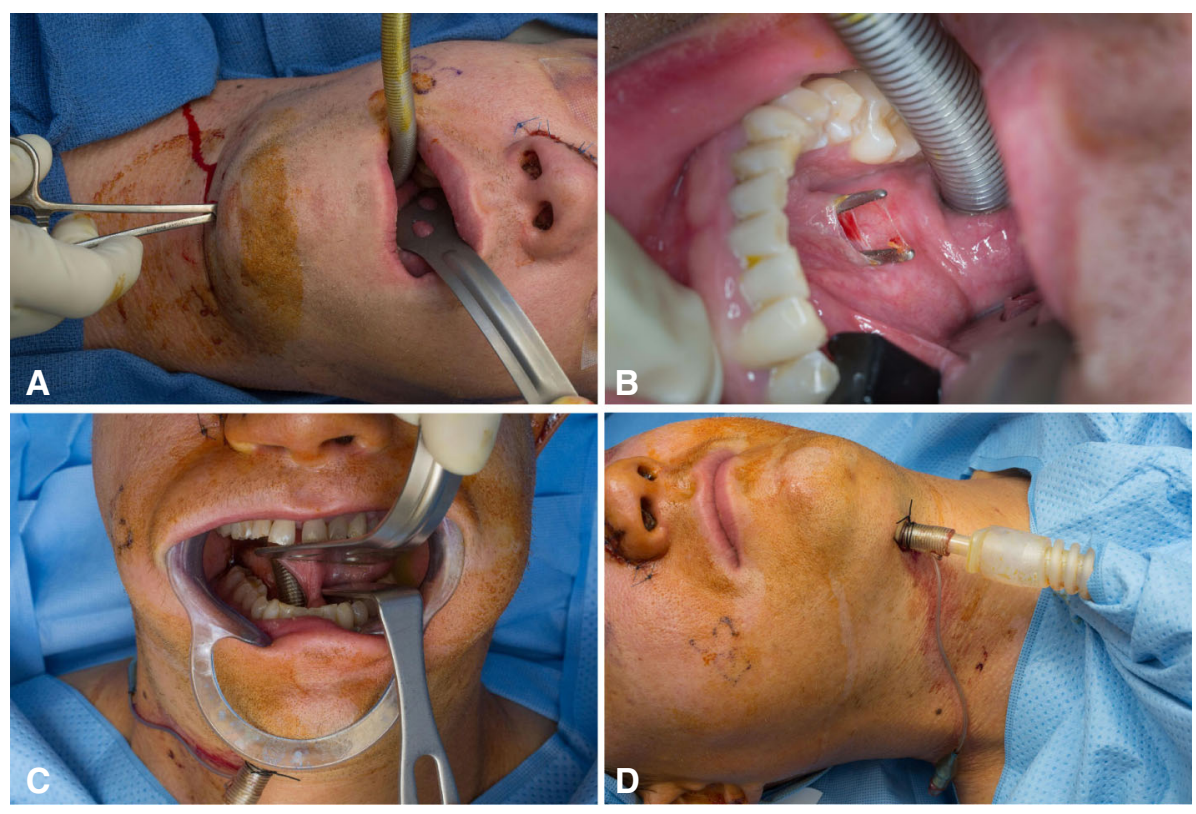

contraindicated and short-term intubation is expected. Vigilance is crucial during ETT manipulation as this may result in inadvertent dislodgement, mainstem intubation, and ETT damage. ${ }^{1,2}$ Extubation directly through the submental tunnel (followed by skin closure) is another approach though it is primarily used in patients requiring maxillomandibular fixation. ${ }^{3}$ Complications following submental intubation are minor, and considerably fewer, compared with tracheostomy. ${ }^{1}$ Superficial skin infections at the submental incision site have been previously reported; therefore, postoperative management entails daily surveillance of the incision and routine wound care. ${ }^{1}$

Overall, a submental intubation is a simple and effective airway technique for craniomaxillofacial surgery in dentate patients that require establishment of occlusion without the need for prolonged postoperative ventilation.
Editorial responsibility This submission was handled by Dr. Hilary P. Grocott, Editor-in-Chief, Canadian Journal of Anesthesia.

\section{References}

1. Jundt JS, Cattano D, Hagberg CA, Wilson JW. Submental intubation: a literature review. Int J Oral Maxillofac Surg 2012; 41: 46-54.

2. Eisemann B, Eisemann $M$, Rizvi M, Urata MM, Lypka MA. Defining the role for submental intubation. J Clin Anesth 2014; 26 : 238-42.

3. Emara TA, El-Anwar MW, Omara TA, Anany A, Elawa IA, Rabea $M M$. Submental intubation versus tracheostomy in maxillofacial fractures. Oral Maxillofac Surg 2019; 23: 337-41.

Publisher's note Springer Nature remains neutral with regard to jurisdictional claims in published maps and institutional affiliations.

Disclosures None.

\section{Funding statement None.}

